\title{
Initiation, Propagation, and Termination of Partial (Focal) Seizures
}

\author{
Marco de Curtis ${ }^{1}$ and Massimo Avoli ${ }^{2,3}$ \\ ${ }^{1}$ Unit of Epileptology and Experimental Neurophysiology and Fondazione Istituto Neurologico \\ Carlo Besta, 20133 Milano, Italy \\ ${ }^{2}$ Montreal Neurological Institute and Departments of Neurology and Neurosurgery and Physiology, \\ McGill University, Montréal, H3A 2B4 Québec, Canada \\ ${ }^{3}$ Department of Experimental Medicine, Facoltà di Medicina e Odontoiatria, Sapienza Università \\ di Roma, 00185 Roma, Italy \\ Correspondence: decurtis@istituto-besta.it
}

The neurophysiological patterns that correlate with partial (focal) seizures are well defined in humans by standard electroencephalogram (EEG) and presurgical depth electrode recordings. Seizure patterns with similar features are reproduced in animal models of partial seizures and epilepsy. However, the network determinants that support interictal spikes, as well as the initiation, progression, and termination of seizures, are still elusive. Recent findings show that inhibitory networks are prominently involved at the onset of these seizures, and that extracellular changes in potassium contribute to initiate and sustain seizure progression. The end of a partial seizure correlates with an increase in network synchronization, which possibly involves both excitatory and inhibitory mechanisms.

$P_{t}$ artial (focal) seizures are transient events that occur without warning as the result of the pathological activation of cortical areas with disregulated excitability. The pathogenic background of partial seizures is sustained by complex structural and functional alterations of neurons and glia, and may also involve changes in the extracellular matrix (Dityatev et al. 2010), neuro-glio-vascular interactions, and bloodbrain barrier function (Wetherington et al. 2008; Seifert et al. 2010; Marchi et al. 2014). These modifications presumably result from an epileptogenic process triggered by the excitotoxic damage associated with the primary insult (trauma, anoxia, inflammation, etc.).
Because of their dependence on an initial pathogenic trigger, focal symptomatic epilepsies have been classified in the most recent proposal of the International League Against Epilepsy (ILAE) as epilepsies caused by structural-metabolic etiology (Berg et al. 2010; Berg and Scheffer 2011).

The electrographic epileptiform patterns expressed during a partial seizure are distinctive for the structures and networks entrained by the seizure discharge and, with some exceptions (see below), they are thought to be independent of the original primary insult (Pelliccia et al. 2013; Perucca et al. 2014). The existence of system-specific susceptibility to seizures and epi-

Editors: Gregory L. Holmes and Jeffrey L. Noebels

Additional Perspectives on Epilepsy: The Biology of a Spectrum Disorder available at www.perspectivesinmedicine.org

Copyright (C) 2015 Cold Spring Harbor Laboratory Press; all rights reserved; doi: 10.1101/cshperspect.a022368

Cite this article as Cold Spring Harb Perspect Med 2015;5:a022368 
lepsy is supported by the demonstration that arterial perfusion of proconvulsive drugs induce acute interictal and ictal epileptiform patterns, which are segregated to specific cortical systems (Librizzi and de Curtis 2003; Boido et al. 2014a). Moreover, it is well known in animal models that focal chronic alterations that mimic temporal lobe epilepsy (TLE) can arise from a generalized "status epilepticus" induced by intraperitoneal treatment with convulsants, such as pilocarpine or kainic acid. This evidence suggests, therefore, a specific vulnerability of the temporal lobe system to systemic treatments (see Avanzini et al. 2012). This experimental evidence also supports the concept that specific and restricted cortical networks/systems are prone to generate seizures (Avanzini et al. 2012). In line with this view, the concept of "epileptic network" is more appropriate than the term "epileptic focus" to describe the brain area of altered tissue involved in a focal seizure. In this review, we will, therefore, use "epileptic network" as a replacement for "epileptic focus," but we will retain the term "partial" to describe seizures attributable to localized epileptic network activation.

The notion of epileptogenic or ictogenic network is also supported by the analysis of seizure patterns and activity distribution observed during presurgical electroencephalogram (EEG) monitoring, with intracranial and intracerebral electrodes in patients with partial epilepsies submitted to epilepsy surgery. These studies have shown that the epileptogenic region (i.e., the area to be surgically removed to cure the patient) is larger than both the epileptogenic lesion and the seizure-onset area (Rosenow and Lüders 2001; Kahane et al. 2006). In the case of human mesial TLE, for instance, seizure activity propagates to extrahippocampal regions, suggesting that the entire temporal lobe is involved (Spencer and Spencer 1994; Bartolomei et al. 2001). These functional data are supported by the demonstration that the histopathological damage in mesial TLE cannot be considered "focal," because it includes different hippocampal and parahippocampal structures with variable rostrocaudal extension (Moran et al. 2001; Ogren et al. 2009; Tassi et al. 2010). Finally, in- tracranial microelectrode recordings in humans have shown that partial seizure may initiate in different areas or microregions within the epileptogenic zone (Stead et al. 2010), suggesting that the paroxysmal activity generated at distant sites within an epileptogenic network contributes to ictal onset patterns observed with the diagnostic macroelectrodes (Bartolomei et al. 2001; Wendling et al. 2003).

The network mechanisms that contribute both to the generation of interictal discharges recorded between seizures and to the onset, progression, and end of partial seizures are still largely unexplained. In the first part of this report, we will review the processes that presumably initiate, sustain, and terminate a partial seizure. In the second part, we will analyze the correlation between interictal events and ictal discharges (de Curtis and Avanzini 2001; de Curtis et al. 2012; Avoli et al. 2013a).

\section{SEIZURE PATTERNS}

Partial seizures are self-terminating events, which typically last 2-6 min (Jenssen et al. 2006). In humans, their electrographic patterns can be characterized with different levels of detail, depending on the recording approach. Scalp EEG recordings are valuable to detect seizure propagation on the entire cortical mantle, ipsi-, and contralateral to the epileptogenic region, but they are not ideal to identify the onset patterns and area of seizure initiation (Pacia and Ebersole 1997). Scalp EEG recording is technically undemanding and shows that partial seizures correlate with large amplitude, rhythmic activity. Focal postictal slowing characterized by large amplitude activity in the " $\delta$ " frequency range is often seen at the end of the seizure. The onset of partial seizures recorded on the scalp is marked by a "flattening" of EEG signal and by the appearance of low amplitude and fast rhythms (Gloor 1975; Fariello et al. 1979).

Long-term intracranial recordings performed in surgical cases to locate the epileptogenic region are more accurate than scalp EEG to describe seizure patterns in proximity to the generators of the ictal discharge. With some exceptions, seizure patterns recorded in different 
lobes and cortical areas do not differ substantially. In a recent report, among seven types of intracranial EEG seizure patterns identified in a population of patients with partial epilepsies caused by different etiologies (Perucca et al. 2014), two were the most commonly observed (see below). Ictal patterns specific for the underlying epileptogenic lesion have been described in type IIb focal cortical dysplasias (Tassi et al. 2002), periventricular heterotopias (Tassi et al. 2005), and mesial TLE with massive cell loss and gliosis (Spencer and Pappas 1992; Ogren et al. 2009).

Unlike seizure patterns in generalized idiopathic epilepsies, which present with sequences of large amplitude EEG oscillations (e.g., spike and wave complexes) virtually unmodified from the beginning to the end of the seizure, human "partial seizures show an evolving pattern that changes over time." A typical partial seizure recorded with depth electrodes initiates either with low-voltage fast activity or "hypersynchro- nous" potentials. This initial phase is followed by an irregular large amplitude activity, often defined as tonic discharge that evolves into phasic (clonic) activity characterized by rhythmic bursting followed by periods of electrical depression (Fig. 1) (de Curtis and Gnatkovsky 2009).

Long-term in vivo EEG monitoring in animal models of partial epilepsies show seizure patterns similar to those identified in human partial epilepsies. Evolving patterns are commonly observed in posttraumatic and poststroke epilepsy models (Pitkänen et al. 2006; Kadam et al. 2010), in models of mesial TLE either secondary to pharmacologically induced status epilepticus (Williams et al. 2009; Bortel et al. 2010; Levesque et al. 2012), or induced by kindling (Michalakis et al. 1998). As in humans, seizures in experimental animals with partial epilepsy occur randomly, often in clusters (Grabenstatter et al. 2005; Goffin et al. 2007; Williams et al. 2009).
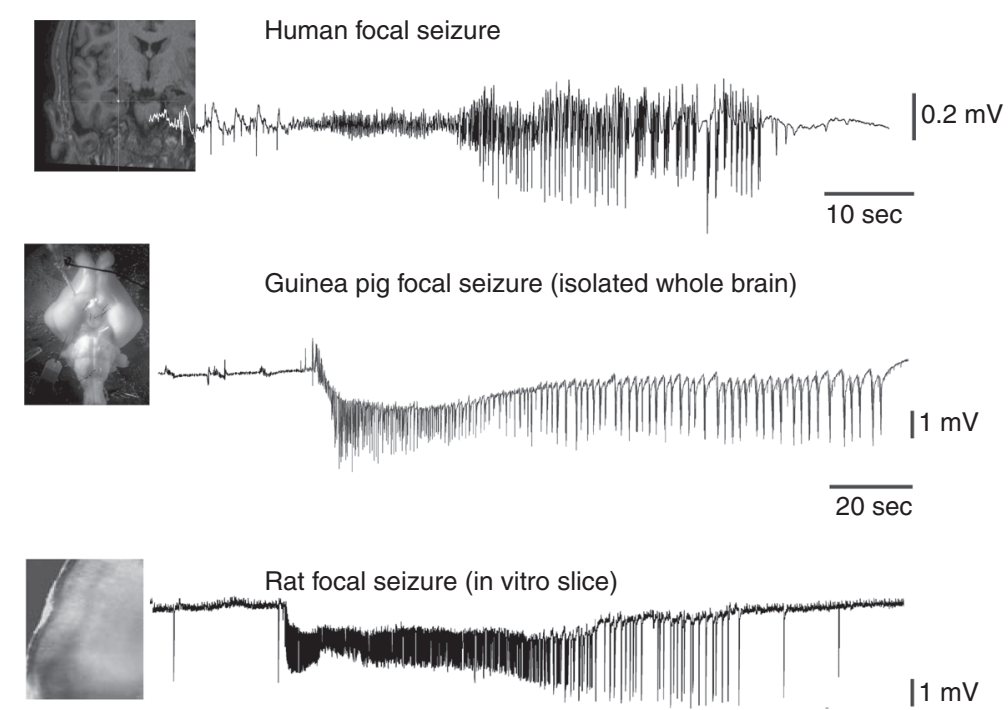

$50 \mathrm{sec}$

Figure 1. Focal (partial) seizure patterns recorded with depth electrodes in the hippocampus of a patient suffering from human temporal lobe epilepsy (TLE) during presurgical stereo electroencephalogram (EEG) monitoring (upper trace: magnetic resonance image on the left, kindly provided by Stefano Francione), in the CA1 hippocampal region of the in vitro isolated guinea pig brain during bicuculline perfusion (middle panel: picture of the in vitro brain on the left), and in a temporal lobe slice maintained in vitro after perfusion with 4-aminopyridine (4AP) (bottom panel: picture of the slice on the left). 
In in vitro preparations (brain slices and in toto preparations) isolated from chronically epileptic animals, interictal activity can be seen, but seizures do not occur spontaneously and are usually evoked by either pharmacological manipulations or patterned stimulations. The absence of spontaneous seizures in in vitro preparations is presumably a result of the restricted network preserved following the slicing procedure, as well as other factors (e.g., fragmentation of neuro-glio-vascular interactions, release of factors during the slicing procedure, etc.). In most in vitro neocortical or hippocampal slices treated with convulsants (but not all; see Avoli and Williamson 1996; Avoli et al. 2002), seizure patterns do not show the typical progression of partial seizures observed in vivo. This is possibly a result of the factors mentioned above and should be carefully considered when in vitro preparations are used to study focal ictogenesis. However, when brain slices containing broader networks are used (e.g., slices comprising the entorhinal and hippocampus), seizures with an evolving pattern similar to the in vivo condition are induced by pharmacological manipulations (Avoli and Williamson 1996; Avoli et al. 2002; Avoli and de Curtis 2011).

\section{SEIZURE ONSET}

Scalp EEG recordings in humans show that the most frequent marker of seizure onset is a reduction in the amplitude of background activity coupled with the appearance of fast activity in the $\beta-\gamma$ range (so-called EEG flattening; Gloor 1975; Fariello et al. 1979; de Curtis and Gnatkovsky 2009). Clinical studies based on longterm intracranial depth recordings from the epileptogenic zone during presurgical stereo-EEG monitoring confirmed that the most common pattern at seizure onset is characterized by the abolition of background activity that is replaced by low-voltage fast activity at $20-100 \mathrm{~Hz}$ (" $\beta$ $\gamma$ ” range) (Allen et al. 1992; Fisher et al. 1992; Gotman et al. 1995; Gnatkovsky et al. 2011), which is often superimposed to a very slow potential (Ikeda et al. 1999; Bragin et al. 2007; Gnatkovsky et al. 2014; Wu et al. 2014). Lowvoltage fast activity has a critical localizing/ lateralizing value, and is detected in the large majority of intracranially explored partial epilepsies, such as TLEs, focal cortical dysplasias, and postanoxic lesions (Gotman et al. 1995; Pelliccia et al. 2013). This EEG pattern is observed in the majority of intracranially explored partial epilepsies, such as TLEs, focal cortical dysplasias, and postanoxic lesions. Another common seizure-onset pattern, defined as hypersynchronous, is characterized by large-amplitude spike potentials (Engel et al. 1990; Maillard et al. 2004). The hypersynchronous pattern is most often seen in TLEs with hippocampal sclerosis (Spencer et al. 1992; Ogren et al. 2009) and was never reported in neocortical focal epilepsies. Other less frequent patterns of seizure initiation have been described (Perucca et al. 2014) and are interpreted as either propagated activity or "far fields," which are volume-conducted from the cortical generators. These patterns, therefore, do not localize the epileptogenic network.

Both low-voltage fast activity and hypersynchronous seizure-onset patterns are typically observed in animal models of mesial TLE (Engel et al. 1990; Bragin et al. 1999; Levesque et al. 2012) and in models of acute temporal seizures (Bragin et al. 1999; Zhang et al. 2012; Levesque et al. 2013; Boido et al. 2014a). These two patterns may be the expression of the activation of the same networks, because the large-amplitude spikes typically detected in the hypersynchronous pattern are often followed by short runs of low-voltage fast activity (Perucca et al. 2014). In line with the concept of the epileptic network, experimental work has shown that both patterns are generated by the limbic system in vivo in the pilocarpine model of mesial TLE (Levesque et al. 2012), and in the in vitro whole guinea pig brain treated with different proconvulsive drugs, such as bicuculline or 4-aminopyridine (4AP) (Uva et al. 2005; Carriero et al. 2010; Boido et al. 2014a).

Further insight to the cellular mechanisms underlying low-voltage fast activity and hypersynchronous seizure onsets, rests on in vivo data obtained by analyzing the high-frequency oscillations (HFOs) occurring during the preictal and ictal periods in pilocarpine-treated epi- 
leptic rats. HFOs are categorized as ripples $(80-$ $200 \mathrm{~Hz}$ ) and fast ripples $(250-500 \mathrm{~Hz}$ ) (Jefferys et al. 2012a), and it has been proposed that ripples represent inhibitory postsynaptic potentials (IPSPs) generated by principal neurons entrained by synchronously active interneuron networks (Ylinen et al. 1995), whereas fast ripples reflect synchronous in-phase or out-ofphase firing of abnormally active (Jefferys et al. 2012) principal cells, thus being independent of inhibitory neurotransmission (Dzhala and Staley 2004; Foffani et al. 2007; Engel et al. 2009; Ibarz et al. 2010; Bragin et al. 2011). According to the findings reported by Avoli and colleagues (Levesque et al. 2012), low-voltage fast activity seizures are mainly associated with increased ripple rates, whereas hypersynchronous seizures are mostly accompanied by fast ripples. Moreover, the increases in occurrence of fast ripples during hypersynchronous seizures and ripples during low-voltage fast activity seizures are mostly occurring in seizureonset zones, suggesting that they could reflect distinct, as well as specific, mechanisms of ictogenesis (Levesque et al. 2012).

Low-voltage fast activity and hypersynchronous onset patterns can also be reproduced in a combined hippocampus-entorhinal cortex, or hippocampus amygdala slices perfused in vitro with either 4AP (Lopantsev and Avoli 1998; Avoli et al. 2013b), low-magnesium and highpotassium solution (Derchansky et al. 2006; Zhang et al. 2012), as well as following highfrequency tetanic stimulation (Isomura et al. 2008; Fujiwara-Tsukamoto et al. 2010). In these in vitro models, low-voltage fast activity onset is characterized at the start by a prominent activation of inhibitory interneurons (Velazquez and Carlen 1999; Kohling et al. 2000; Ziburkus et al. 2006; Lasztoczi et al. 2009; Fujiwara-Tsukamoto et al. 2010), which transiently shut off principal cells (Fig. 2A) (Gnatkovsky et al. 2008). In the in vitro isolated guinea pig brain preparation, enhanced activity of inhibitory neurons in the entorhinal cortex lasting several seconds was consistently observed in correspondence with low-voltage fast activity induced by either low concentrations of bicuculline or 4AP (Gnatkovsky et al. 2008; Uva et al. 2009). During this initial period, principal neurons of superficial and deep layers of the entorhinal cortex were silent and resumed firing when inhibition was presumably neutralized by the changes in extracellular potassium associated with interneuronal firing (see below) (Gnatkovsky et al. 2008; Trombin et al. 2011). The enhanced activation of the potassium-chloride cotransporter KCC2 in principal neurons during synchronous inhibitory GABAergic activation has been proposed as a potential mechanism of the potassium elevations that are associated with the onset of the ictal discharge (see Figs. $2 \mathrm{~B}$ and $4 \mathrm{~A}$, as well as the next paragraph) (Lopantsev and Avoli 1996; Viitanen et al. 2010). The role of large amplitude preictal GABAergic potential in driving the epileptogenic network into seizure will be discussed in the last paragraph (see below).

Trevelyan and colleagues $(2006,2007)$ proposed that the increase of inhibitory network activity just ahead of a seizure may reflect the attempt of the network to impede seizure precipitation by imposing a feedforward inhibition on excitatory networks. When such inhibition fails, seizure activity characterized by hyperactivity of principal neurons ensues (Trevelyan et al. 2006, 2007). This interpretation was also suggested by Cammarota et al. (2013), who analyzed the propagation of seizures induced by local application of $N$-methyl-D-aspartate (NMDA) in the entorhinal and temporal cortex in a brain slice preparation. The failure of inhibition to control seizure activity in this model is caused by a depolarizing block of interneurons (Cammarota et al. 2013), a phenomenon that was never shown in vivo. A depolarizing block of the firing generated by inhibitory cells was also proposed as a seizure-initiation event in another model of acute seizures in the immature hippocampus in vitro (Derchansky et al. 2006; Ziburkus et al. 2006; Holler et al. 2011). However, the reduction of interneuron activity as responsible for the recruitment of principal cells has not been shown in these models. Interestingly, a prominent bursting activity of interneurons is observed at the very onset of the seizure in these studies. The hypersynchronous seizure onset detected in these models is differ- 
M. de Curtis and M. Avoli

A

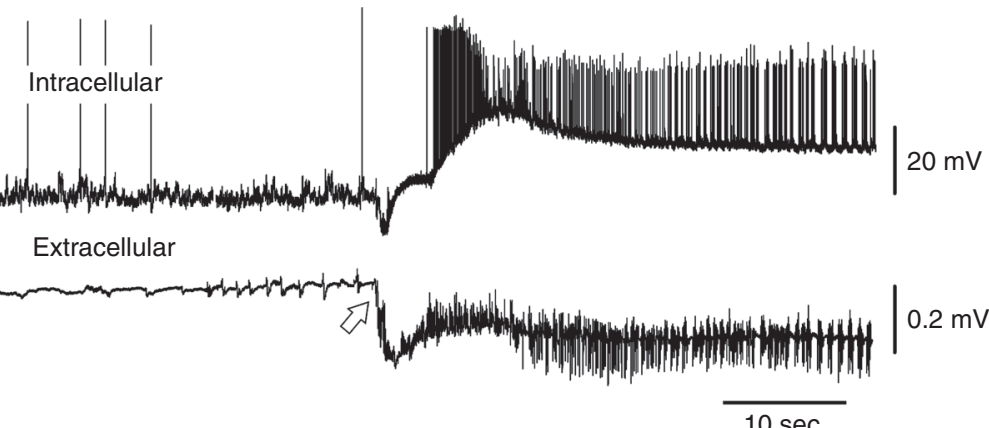

B

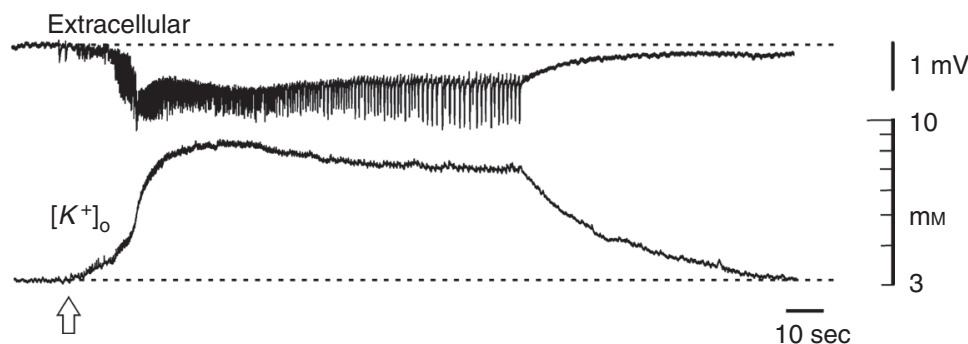

Figure 2. Focal seizure onset in vitro. (A) Simultaneous intracellular (upper trace) and extracellular (lower trace) recordings from the entorhinal cortex of the isolated guinea pig brain during a seizure induced by 4 -aminopyridine (4AP). Seizure onset (marked by the arrow) correlates with a hyperpolarizing transient followed by neuronal depolarization. (B) Simultaneous recording of field potentials and changes in the extracellular concentration of potassium $\left(\left[\mathrm{K}^{+}\right]_{\mathrm{o}}\right)$ during a seizure induced by bicuculline in the entorhinal cortex of the isolated guinea pig brain.

ent from the low-voltage fast activity pattern seen during partial seizures in chronic epilepsy models and in humans.

Hypersynchronous pattern at seizure onset is most consistently observed when cortical excitability is enhanced in brain slices by a solution containing low magnesium and high potassium (Derchansky et al. 2006; Lasztoczi et al. 2009; Zhang et al. 2012). In these conditions, a gradual recruitment of both inhibitory and excitatory networks occurs (Derchansky et al. 2008). Zhang and colleagues (2012) confirmed that, also during the hypersynchronous seizure onset, the interictal and early preictal states are dominated by GABAergic activity, and that seizure onset coincides with (or is, perhaps, heralded by) exhaustion of presynaptic release of GABA, associated with unopposed increased glutamatergic events. A buildup of glutamatergic synaptic excitation with progressive recruit- ment of neurons was suggested to be responsible for the hyperexcitable state during transition to seizure in both experimental in vitro preparations (Cossart et al. 2001; Trotter et al. 2006; Derchansky et al. 2008), and postsurgical human tissue studied in vitro (Huberfeld et al. 2011). According to what is discussed above, an increase of inhibitory network activity is consistently observed at seizure onset. However, whether this process represents the very onset of a seizure, or the ultimate attempt to impede seizure outburst in a hyperexcitable network, is still an unresolved issue.

A decrease in neuronal activity of principal cells at seizure onset was recently confirmed during partial seizures recorded in the hippocampus of epileptic rats after pilocarpine-induced "status epilepticus" (Grasse et al. 2013). In this study of unit activity performed with tetrode electrodes, the decrease in firing gener- 
ated by principal neurons was preceded by an increase in the activity of units identified as inhibitory interneurons. A reduction of unit activity at seizure onset was seen also in multiunit studies performed during presurgical intracranial monitoring in drug-resistant patients with partial epilepsy (Truccolo et al. 2011; Bower et al. 2012; Schevon et al. 2012), suggesting that dampening of neuronal firing at the very beginning of a partial seizure occurs in epileptic patients as well.

As a correlate of the evidence summarized above, low-voltage fast activity in the $\beta / \gamma$ range substitutes in humans the background rhythmic activity, suggesting that a selective synchronization in a narrow frequency band, rather than a synchronization of large amplitude discharges, occurs at seizure onset. A reduction in synchronization during the early phases of a seizure was shown in patients by intracranial multichannel EEG signal analysis (Mormann et al. 2003; Schindler et al.2007a), in cortical and hippocampal slices maintained in vitro (Netoff and Schiff 2002), and by unit activity recordings in models of drug-induced hippocampal seizures in vivo (Cymerblit-Sabba and Schiller 2012). Therefore, diffuse and widespread synchronization is not a typical pattern at the beginning of most partial seizures observed in humans and animals (Jiruska et al. 2013).

\section{SEIZURE MAINTENANCE AND TERMINATION}

After seizure onset, characterized by low-voltage fast or hypersynchronous patterns, a transition into a tonic discharge is consistently observed in partial seizures recorded intracranially in humans and animal models (Lopantsev and Avoli 1998; de Curtis and Gnatkovsky 2009). This transition may result from changes in extracellular potassium associated with the increased activity in interneurons (or in principal neurons, according to the alternative KCC2 hypothesis; see below) on network excitability. Several studies by the German school (Heinemann et al. 1977) showed that seizure onset correlates with extracellular enhancements in potassium. Later studies showed that synchronous activation of inhibitory networks is sufficient to generate large changes in extracellular potassium concentration (Avoli et al. 1996b; Avoli and de Curtis 2011). As mentioned above, an inhibitory network-driven increase in extracellular potassium is also contributed by the neuronal $\mathrm{KCl}$ cotransporter, KCC2, which mediated $\mathrm{KCl}$ extrusion from principal neurons during GABAergic inhibition (Viitanen et al. 2010). According to this view, inhibitory network activity and the consequent release of GABA by interneurons massively activated $\mathrm{GABA}_{\mathrm{A}}$ receptors, leading to intracellular accumulation of chloride that, in turn, forces KCC2 to extrude potassium.

The increased extracellular potassium, in turn, influences inhibition by reducing the electrochemical drive of chloride ions, and results in a reduction in the inhibitory constrain imposed by the inhibitory network activity observed at seizure onset. In the isolated guinea pig brain, transition from low-voltage fast activity into tonic firing correlated with the increases in extracellular potassium (Trombin et al. 2011). In this study, it was suggested that the elevated potassium could directly induce ectopic firing in principal neurons (but, see also Avoli et al. 1998; Avoli and de Curtis 2011). The decrease in inhibition coupled with ectopic firing may reinforce excitatory interactions between principal cells that reciprocally recruit and generate the firing typically observed during the tonic discharge.

In all partial seizures described in epileptic patients or animals, as well as in acute seizures induced by pharmacological manipulations, a transition from tonic firing into rhythmic bursting (also referred to as "clonic" phase of the seizure, an indefinite term derived from the clonic contractions observed at the end of a generalized seizure) is consistently observed. This tonic-to-bursting transition could be accounted for by the progressive synchronization of neuronal firing that occurs when principal neurons are reactivated during the tonic phase. Large amplitude activity synchronized in time and in space represented by large amplitude bursts typically develops at the end of a partial seizure, strongly suggesting that synchroniza- 
M. de Curtis and M. Avoli

tion of excitation may be involved in seizure termination (Topolnik et al. 2003; Jiruska et al. 2013). Resynchronization of intracranial signals during the late seizure phase was shown in human partial seizures (Wendling et al. 2003; Schindler et al. 2007b), suggesting that networks are fragmented at seizure onset and merge during seizure progression, to form a single dominant component before seizure termination (Kramer et al. 2012).

Progressive enhancement of burst activity during the late phase of seizures is associated with a parallel increase of the interburst interval, suggesting that enhanced excitation (burst activity) and enhanced inhibition (postburst inhibition/depression) may develop in parallel when seizures come to an end (Fig. 3). Analysis of responses to local stimulation just suprathreshold for burst generation during focal seizures recorded in the isolated guinea pig brain preparation confirmed that interburst intervals correlated with an inhibition/depression lasting 1-2 sec (Boido et al. 2014b). These data show that conflicting enhancement of both excitation and the ensuing inhibition char- acterize the end of a focal seizure and suggest that long postburst depression during the late ictal phase may stop the seizure by preventing further reactivation of the network (Boido et al. 2015). Postburst inhibition/depression was also shown after interictal spikes in the cat hippocampus in vivo (Lebovitz 1979), the olfactory cortex of the isolated guinea pig brain (de Curtis et al. 2001), and human neocortex of patients with partial epilepsy (de Curtis et al. 2005). A postburst refractory period may be caused by synaptic inhibitory potentials that resume in late phase of seizures (Isomura et al. 2008), activity-dependent changes in ion concentrations $\left(\mathrm{K}^{+}, \mathrm{Cl}^{-}, \mathrm{Ca}^{2+}\right)$ and $\mathrm{pH}$ (Bragin et al. 1997; Velísek 1998), or by inhibitory neuromodulators, such as adenosine (During and Spencer 1992; Boison 2013).

Interestingly, seizure termination characterized by synchronous periodic bursting involves cortical areas more diffusely than at seizure onset. These rather consistent and intriguing findings might be explained by considering the involvement of subcortical structures. After the end of a partial seizure, postictal depression is
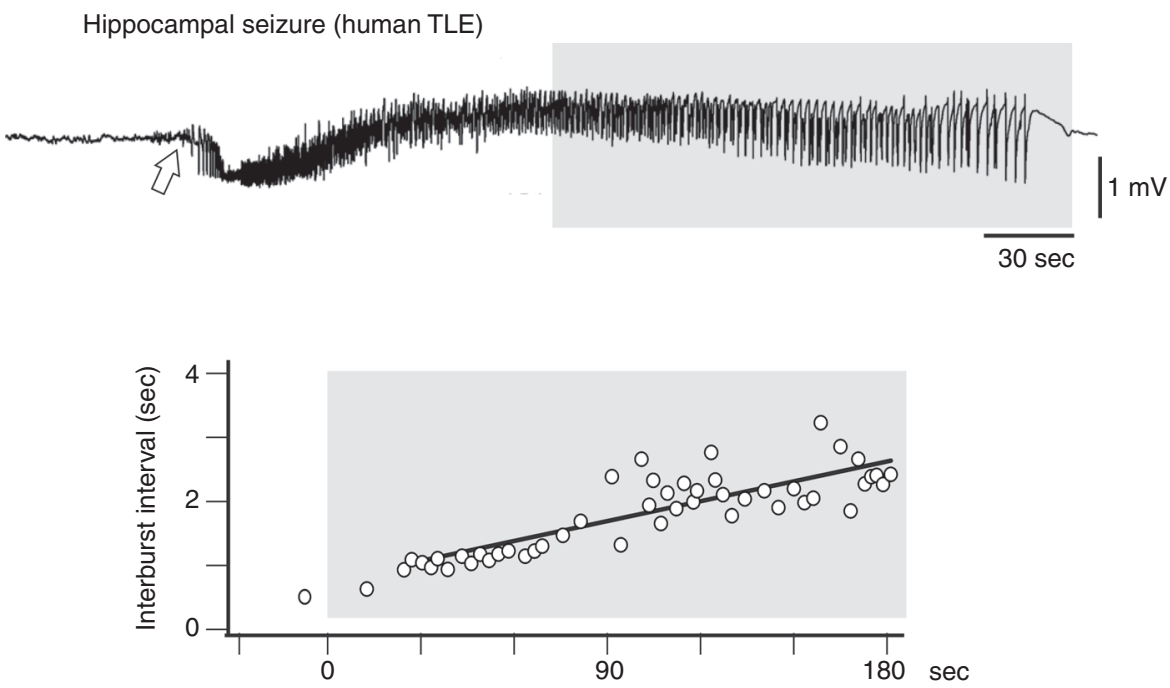

Figure 3. Partial seizure recorded from the hippocampal region of a patient with partial epilepsy during presurgical stereo-EEG monitoring (kindly provided by Stefano Francione). The seizure is characterized by fast activity at onset, followed by tonic activation, and terminates with bursting activity that progressively slows down before seizure end. The closing phase of the seizure correlates with a progressive increase in interburst interval, measured in the shaded area outlined on the EEG trace (see Boido et al. 2014b). TLE, temporal lobe epilepsy. 
evident and can be measured as a reduction of background activity in comparison with the preictal condition.

\section{INTERICTAL EVENTS AND SEIZURES}

Pathological epileptiform activity (termed interictal discharge or spike) can be recorded in the EEG between seizures. Interictal discharges assume different forms, the most common being spikes and sharp waves along with HFOs (see Gotman 1984; de Curtis and Avanzini 2001; Engel et al. 2009; Avoli and de Curtis 2011; de Curtis et al. 2012; Jefferys et al. 2012b). Early, presurgical studies, which were focused on the analysis of the distribution of interictal spikes, showed that the area of spike/sharp wave generation, defined as irritative zone (Talairach and Bancaud 1966), is usually larger than the epileptogenic/seizure-onset zone.

Overall, no coherent relationship has been found between seizure and interictal spike occurrence. For instance, pioneering animal studies on acute seizures induced by topical application of proepileptic agents, such as penicillin, to the cortex suggested that the transition to seizure is characterized by acceleration of interictal spikes (Dichter and Spencer 1969; Ayala et al. 1973). Similar findings were also reproduced in acute, drug-induced seizures in in vitro models (Chamberlin et al. 1990). Extensive work achieved in patients during scalp EEG and intracranial recordings (Lieb et al. 1976; Lange et al. 1983; Gotman 1984; Katz et al. 1991; de Curtis and Avanzini 2001) and in chronic animal models of epilepsy (Ralston 1958; Elazar and Blum 1974; Gotman 1984; Sherwin 1984; Leung et al. 1990) showed that the rate of interictal discharges can either increase or decrease just ahead of a seizure. Therefore, these findings suggest that although interictal spikes/sharp waves are pathological events generated by the epileptic network, they are not necessarily correlated to seizure occurrence.

Experimental and clinical data have, however, shown that sustained interictal spiking, either spontaneously occurring or promoted by low-frequency stimulation, reduces the probability to generate a seizure discharge (Fig. 4)
(Nakagawa and Durand 1991; Barbarosie and Avoli 1997; Librizzi and de Curtis 2003; Tellez Zenteno 2006; Koubeissi et al. 2013). Activitydependent changes in excitability, $\mathrm{pH}$, and gap-junction coupling should contribute to the ability of frequent interictal spiking to prevent the occurrence of seizures. In addition, in vitro evidence suggests that a main player in controlling ictogenesis might rest on the ability of recurring interictal spikes to decrease the transient elevations in extracellular potassium that, at least experimentally, appear to be instrumental for ictal discharge onset (Barbarosie et al. 2002; Avoli et al. 2013a).

Large amplitude preictal spikes are commonly observed in limbic areas just ahead of seizure onset in patients with TLE (Lange et al. 1983; Bragin et al. 2005; Wendling et al. 2005). Several experimental studies also confirmed that preictal spikes are consistently observed before seizures induced by acute pharmacological treatments (Avoli 1990; Avoli et al. 1996a; Lopantsev and Avoli 1998; Gnatkovsky et al. 2008; Carriero et al. 2010). Avoli and collaborators showed that ictal discharges induced by $4 \mathrm{AP}$ in brain slices of different cortical structures initiated with an inhibitory event that showed the membrane reversal of $\mathrm{GABA}_{\mathrm{A}}$ receptor-mediated synaptic potentials (Lopantsev and Avoli 1998; Avoli and de Curtis 2011). In the isolated guinea pig brain, epileptic spikes that occur between seizures are sustained by glutamatergic transmission, whereas preictal spikes correlate with IPSPs, possibly sustained by activation of inhibitory networks and coupled with depression of neuronal firing in principal excitatory neurons (Gnatkovsky et al. 2008). These findings are at variance with data obtained from in vitro subiculum slices from postsurgical specimens of patients with hippocampal sclerosis. In this model, interictal spikes are abolished by the $\mathrm{GABA}_{\mathrm{A}}$ receptor antagonist, whereas preictal spikes induced by a complex proepileptic solution are supported by glutamatergic networks (Huberfeld et al. 2007, 2011). Preictal as well as interictal spikes appear to be contributed by both GABAergic and glutamatergic mechanisms (Avoli and de Curtis 2011). 
A

Control

field

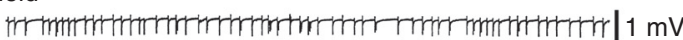

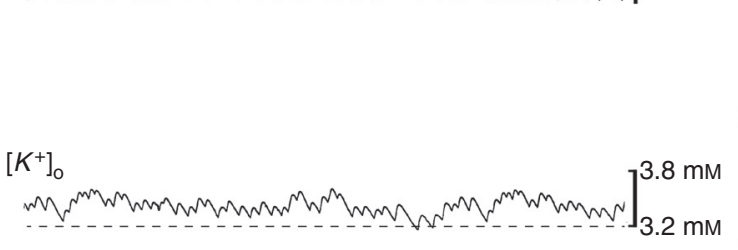

Schaffer collateral

cut

Field
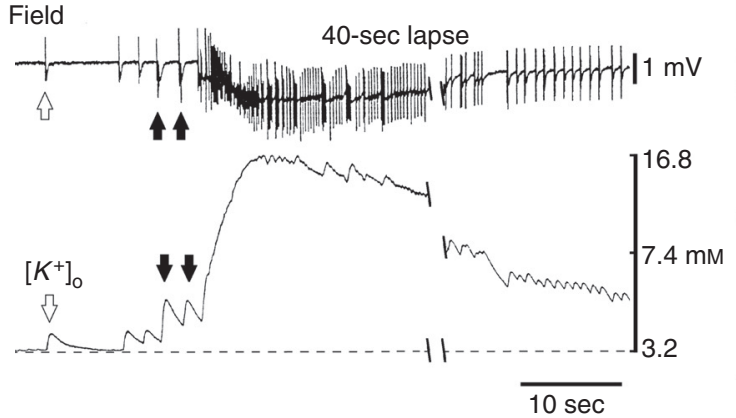

B
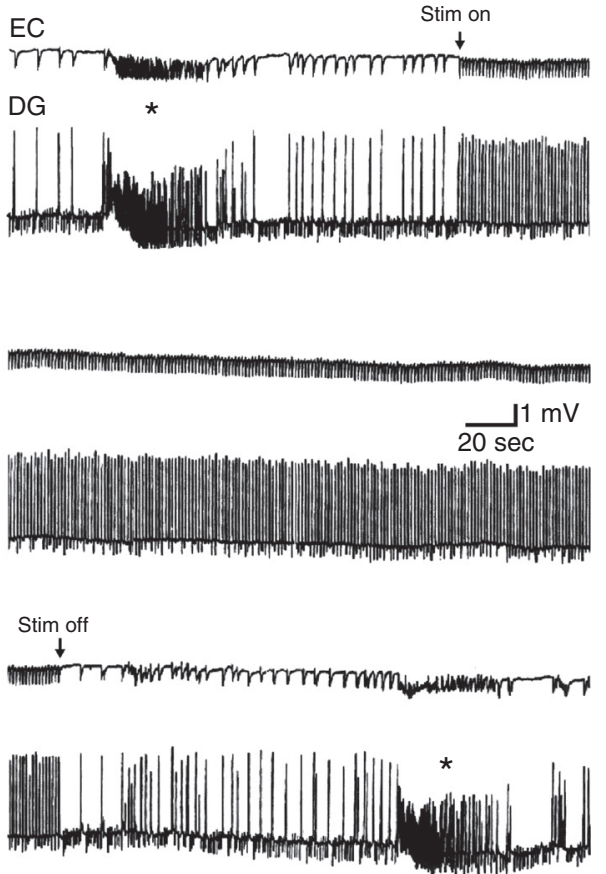

Figure 4. Effects of low-frequency stimulation in vitro. (A) Lesioning the Schaffer collateral changes the pattern of epileptiform activity recorded from the entorhinal cortex (EC) in a combined mouse brain slice with field and potassium-selective microelectrodes. Under control conditions, EC neuronal networks generate fast interictal activity, which is driven by inputs arising in the CA3 subfield of the hippocampus. Cutting the Schaffer collateral prevents CA3-driven interictal activity from propagating the EC and uncovers slow interictal events, along with ictal discharge in this area. Note that the slow interictal spike (open arrows) is associated with an increase in extracellular potassium that is smaller than what occurs in coincidence with the spikes leading to ictal activity (black arrows). Note, also, the much larger elevation in extracellular potassium $\left(\left[\mathrm{K}^{+}\right]_{\mathrm{o}}\right)$ occurring during the overt ictal discharge. $(B)$ Effects induced by electrical stimuli at $1 \mathrm{~Hz}$ on the epileptiform activity recorded from the entorhinal cortex and the dentate gyrus during 4-aminopyridine (4AP) application. In this slice, the Schaffer collateral was cut at the beginning of the experiment. Note that ictal activity (asterisk) is abolished during the stimulation (stim) period and reappears on termination of the stimulation. DG, Dentate gyrus.

\section{CONCLUSIONS}

We have reviewed the fundamental processes that initiate, sustain, and terminate partial seizures, as well as how interictal and ictal activities correlate. We have, indeed, presented experimental evidence that clearly underscores the role of both excitatory and inhibitory synaptic transmission within neuronal networks, which include principal glutamatergic neurons, along with inhibitory interneurons. However, further mechanisms may play important roles in epileptiform synchronization. For instance, because epileptiform activity both in in vivo and in vitro preparations is accompanied by decreases in extracellular $\mathrm{Ca}^{2+}$ that are incompatible with efficient transmitter release (Pumain et al. 1985), slow changes in extracellular ionic concentrations, which modulate intrinsic excitability, as well as ephaptic interactions, cannot be overlooked (Jefferys et al. 2012b). In addition, astrocytes perform complex tasks that go beyond the well-known function of neurotransmitter uptake/recycling and extracellular potassium buffering; these mechanisms, which are dysfunctional in the epileptic tissue, are also, presumably, involved in hyperexcitability and, thus, seizure generation in epileptic disorders 
(Steinhauser and Boison 2012; Steinhauser et al. 2012; Crunelli and Carmignoto 2013).

\section{ACKNOWLEDGMENTS}

Any previously unpublished work reviewed here was supported by the Italian Health Ministry 2012-2014 to M.d.C. and by grants from the Canadian Institutes of Health Research (CIHR) (Operating Grants 8109 and 74609), Citizens United for Research in Epilepsy (CURE), and the Savoy Foundation to M.A.

\section{REFERENCES}

Allen PJ, Fish DR, Smith SJ. 1992. Very high-frequency rhythmic activity during SEEG suppression in frontal lobe epilepsy. Electroencephalogr Clin Neurophysiol 82: 155-159.

Avanzini G, Manganotti P, Meletti S, Moshe SL, Panzica F, Wolf P, Capovilla G. 2012. The system epilepsies: A pathophysiological hypothesis. Epilepsia 53: 771-778.

Avoli M. 1990. Epileptiform discharges and a synchronous GABAergic potential induced by 4-aminopyridine in the rat immature hippocampus. Neurosci Lett 117: 93-98.

Avoli M, de Curtis M. 2011. GABAergic synchronization in the limbic system and its role in the generation of epileptiform activity. Prog Neurobiol 95: 104-132.

Avoli M, Williamson A. 1996. Functional and pharmacological properties of human neocortical neurons maintained in vitro. Prog Neurobiol 48: 519-554.

Avoli M, Barbarosie M, Lücke A, Nagao T, Lopantsev V, Köhling R. 1996a. Synchronous GABA-mediated potentials and epileptiform discharges in the rat limbic system in vitro. J Neurosci 16: 3912-3924.

Avoli M, Louvel J, Kurcewicz I, Pumain R, Barbarosie M. 1996b. Extracellular free potassium and calcium during synchronous activity induced by 4 -aminopyridine in the juvenile rat hippocampus. J Physiol 493: 707-717.

Avoli M, Methot M, Kawasaki H. 1998. GABA-dependent generation of ectopic action potentials in the rat hippocampus. Eur J Neurosci 10: 2714-2722.

Avoli M, D’Antuono M, Louvel J, Kohling R, Biagini G, Pumain R, D’Arcangelo G, Tancredi V. 2002. Network and pharmacological mechanisms leading to epileptiform synchronization in the limbic system in vitro. Prog Neurobiol 68: 167-207.

Avoli M, de Curtis M, Kohling R. 2013a. Does interictal synchronization influence ictogenesis? Neuropharmacology 69: 37-44.

Avoli M, Panuccio G, Herrington R, D’Antuono M, de Guzman P, Levesque M. 2013b. Two different interictal spike patterns anticipate ictal activity in vitro. Neurobiol Dis 52: $168-176$.

Ayala GF, Dichter M, Gumnit RJ. 1973. Genesis of epilectic interictal spikes. New knowledge of cortical feedback sys- tem suggests a neurophysiological explanation of brief paroxysms. Brain Res 52: 1-17.

Barbarosie M, Avoli M. 1997. CA3-driven hippocampal-entorhinal loop controls rather than sustains in vitro limbic seizures. J Neurosci 17: 9308-9314.

Barbarosie M, Louvel J, D’Antuono M, Kurcewicz I, Avoli M. 2002. Masking synchronous GABA-mediated potentials controls limbic seizures. Epilepsia 43: 1469-1479.

Bartolomei F, Wendling F, Bellanger JJ, Regis J, Chauvel P. 2001. Neural networks involving the medial temporal structures in temporal lobe epilepsy. Clin Neurophysiol 112: $1746-1760$.

Berg AT, Scheffer IE. 2011. New concepts in classification of the epilepsies: Entering the 21st century. Epilepsia 52: 1058-1062.

Berg AT, Berkovic SF, Brodie MJ, Buchhalter J, Cross JH, van Emde Boas W, Engel J, French J, Glauser TA, Mathern GW, et al. 2010. Revised terminology and concepts for organization of seizures and epilepsies: Report of the ILAE Commission on Classification and Terminology, 2005-2009. Epilepsia 51: 676-685.

Boido D, Jesuthasan N, de Curtis M, Uva L. 2014a. Network dynamics during the progression of seizure-like events in the hippocampal-parahippocampal regions. Cereb Cortex 24: $163-173$.

Boido D, Gnatkovsky V, Uva L, Francione S, de Curtis M. 2014b. Simultaneous enhancement of excitation and post-burst inhibition at the end of focal seizures. Ann Neurol 76: 826-836.

Boison D. 2013. Role of adenosine in status epilepticus: A potential new target? Epilepsia 54: 20-22.

Bortel A, Levesque M, Biagini G, Gotman J, Avoli M. 2010. Convulsive status epilepticus duration as determinant for epileptogenesis and interictal discharge generation in the rat limbic system. Neurobiol Dis 40: 478-489.

Bower MR, Stead M, Meyer FB, Marsh WR, Worrell GA. 2012. Spatiotemporal neuronal correlates of seizure generation in focal epilepsy. Epilepsia 53: 807-816.

Bragin A, Penttonen M, Buzsáki G. 1997. Termination of epileptic afterdischarge in the hippocampus. J Neurosci 17: 2567-2579.

Bragin A, Engel JJ, Wilson CL, Vizentin E, Mathern GW. 1999. Electrophysiologic analysis of a chronic seizure model after unilateral hippocampal KA injection. Epilepsia 40: $1210-1221$.

Bragin A, Azizyan A, Almajano J, Wilson CL, Engel JJ. 2005. Analysis of chronic seizure onsets after intrahippocampal kainic acid injection in freely moving rats. Epilepsia 46: 1592-1598.

Bragin A, Claeys P, Vonck K, Van Roost D, Wilson C, Boon P, Engel JJ. 2007. Analysis of initial slow waves (ISWs) at the seizure onset in patients with drug resistant temporal lobe epilepsy. Epilepsia 48: 1883-1894.

Bragin A, Benassi SK, Kheiri F, Engel J Jr, 2011. Further evidence that pathologic high-frequency oscillations are bursts of population spikes derived from recordings of identified cells in dentate gyrus. Epilepsia 52: 45-52.

Cammarota M, Losi G, Chiavegato A, Zonta M, Carmignoto G. 2013. Fast spiking interneuron control of seizure propagation in a cortical slice model of focal epilepsy. J Physiol 591: 807-822. 
Carriero G, Uva L, Gnatkovsky V, Avoli M, de Curtis M. 2010. Independent epileptiform discharge patterns in the olfactory and limbic areas of the in vitro isolated Guinea pig brain during 4-aminopyridine treatment. J Neurophysiol 103: 2728-2736.

Chamberlin NL, Traub RD, Dingledine R. 1990. Role of EPSPs in initiation of spontaneous synchronized burst firing in rat hippocampal neurons bathed in high potassium. J Neurophysiol 64: 1000-1008.

Cossart R, Dinocourt C, Hirsch JC, Merchan-Perez A, De Felipe J, Ben-Ari Y, Esclapez M, Bernard C. 2001. Dendritic but not somatic GABAergic inhibition is decreased in experimental epilepsy. Nat Neurosci 4: 52-62.

Crunelli V, Carmignoto G. 2013. New vistas on astroglia in convulsive and non-convulsive epilepsy highlight novel astrocytic targets for treatment. J Physiol 591: 775-785.

Cymerblit-Sabba A, Schiller Y. 2012. Development of hypersynchrony in the cortical network during chemoconvulsant-induced epileptic seizures in vivo. J Neurophysiol 107: $1718-1730$

de Curtis M, Avanzini G. 2001. Interictal spikes in focal epileptogenesis. Prog Neurobiol 63: 541-567.

de Curtis M, Gnatkovsky V. 2009. Reevaluating the mechanisms of focal ictogenesis: The role of low-voltage fast activity. Epilepsia 50: 2514-2525.

de Curtis M, Librizzi L, Biella G. 2001. Discharge threshold is enhanced for several seconds after a spontaneous interictal spike in a model of focal epileptogenesis. Eur $J$ Neurosci 14: 1-6.

de Curtis M, Tassi L, Lo Russo G, Mai R, Cossu M, Francione S. 2005. Increased discharge threshold after an interictal spike in human focal epilepsy. Eur J Neurosci 22: 29712976.

de Curtis M, Jefferys JGR, Avoli M. 2012. Interictal epileptiform discharges in partial epilepsy: Complex neurobiological mechanisms based on experimental and clinical evidence. In Jasper's basic mechanisms of the epilepsies (ed. Noebels JL, Avoli M, Rogawski MA, Olsen RW, DelgadoEscueta $\mathrm{AV}$ ). National Center for Biotechnology Information, Bethesda, MD.

Derchansky M, Rokni D, Rick JT, Wennberg R, Bardakjian BL, Zhang L, Yarom Y, Carlen PL. 2006. Bidirectional multisite seizure propagation in the intact isolated hippocampus: The multifocality of the seizure "focus." Neurobiol Dis 23: 312-328.

Derchansky M, Jahromi SS, Mamani M, Shin DS, Sik A, Carlen PL. 2008. Transition to seizures in the isolated immature mouse hippocampus: A switch from dominant phasic inhibition to dominant phasic excitation. $J$ Physiol 586: 477-494.

Dichter M, Spencer WA. 1969. Penicillin-induced interictal discharges from the cat hippocampus. I: Characteristics and topographical features. J Neurophysiol 32: 649-662.

Dityatev A, Schachner M, Sonderegger P. 2010. The dual role of the extracellular matrix in synaptic plasticity and homeostasis. Nat Rev Neurosci 11: 735-746.

During MJ, Spencer DD. 1992. Adenosine: A potential mediator of seizure arrest and postictal refractoriness. Ann Neurol 32: 618-624.

Dzhala VI, Staley KJ. 2004. Mechanisms of fast ripples in the hippocampus. J Neurosci 24: 8896-8906.
Elazar Z, Blum B. 1974. Interictal discharges in tungsten foci and EEG seizure activity. Epilepsia 15: 599-610.

Engel JJ, Henry TR, Risinger MW, Mazziotta JC, Sutherling WW, Levesque MF, Phelps ME. 1990. Presurgical evaluation for partial epilepsy: Relative contributions of chronic depth-electrode recordings versus FDG-PET and scalp-sphenoidal ictal EEG. Neurology 40: 16701677.

Engel JJ, Bragin A, Staba R, Mody I. 2009. High-frequency oscillations: What is normal and what is not? Epilepsia 50: 598-604.

Fariello RG, Doro JM, Forster FM. 1979. Generalized cortical electrodecremental event. Clinical and neurophysiological observations in patients with dystonic seizures. Arch Neurol 36: 285-291.

Fisher RS, Webber WR, Lesser RP, Arroyo S, Uematsu S 1992. High-frequency EEG activity at the start of seizures. J Clin Neurophysiol 9: 441-448.

Foffani G, Uzcategui YG, Gal B, Menendez de la Prida L. 2007. Reduced spike-timing reliability correlates with the emergence of fast ripples in the rat epileptic hippocampus. Neuron 55: 930-941.

Fujiwara-Tsukamoto $Y$, Isomura $Y$, Imanishi M, Ninomiya T, Tsukada M, Yanagawa Y, Fukai T, Takada M. 2010. Prototypic seizure activity driven by mature hippocampal fast-spiking interneurons. J Neurosci 30: 13679-13689.

Gloor P. 1975. Contributions of electroencephalography and electrocorticography to the neurosurgical treatment of the epilepsies. Adv Neurol 8: 59-105.

Gnatkovsky V, Librizzi L, Trombin F, de Curtis M. 2008. Fast activity at seizure onset is mediated by inhibitory circuits in the entorhinal cortex in vitro. Ann Neurol 64: 674-686.

Gnatkovsky V, Francione S, Cardinale F, Mai R, Tassi L, Lo Russo G, de Curtis M. 2011. Identification of reproducible ictal patterns based on quantified frequency analysis of intracranial EEG signals. Epilepsia 52: 477-488.

Gnatkovsky V, de Curtis M, Pastori C, Cardinale F, Lo Russo G, Mai R, Nobili L, Sartori I, Tassi L, Francione S. 2014. Biomarkers of epileptogenic zone defined by quantified stereo-EEG analysis. Epilepsia 55: 296-305.

Goffin K, Nissinen J, Van Laere K, Pitkanen A. 2007. Cyclicity of spontaneous recurrent seizures in pilocarpine model of temporal lobe epilepsy in rat. Exp Neurol 205: 501-505.

Gotman J. 1984. Relationships between triggered seizures, spontaneous seizures, and interictal spiking in the kindling model of epilepsy. Exp Neurol 84: 259-273.

Gotman J, Levtova V, Olivier A. 1995. Frequency of the electroencephalographic discharge in seizures of foca and widespread onset in intracerebral recordings. Epilepsia 36: 697-703.

Grabenstatter HL, Ferraro DJ, Williams PA, Chapman PL, Dudek FE. 2005. Use of chronic epilepsy models in antiepileptic drug discovery: The effect of topiramate on spontaneous motor seizures in rats with kainate-induced epilepsy. Epilepsia 46: 8-14.

Grasse DW, Karunakaran S, Moxon KA. 2013. Neuronal synchrony and the transition to spontaneous seizures. Exp Neurol 248: 72-84. 
Heinemann U, Lux HD, Gutnick MJ. 1977. Extracellular free calcium and potassium during paroxsmal activity in the cerebral cortex of the cat. Exp Brain Res 27: 237-243.

Holler Y, Bergmann J, Kronbichler M, Crone JS, Schmid EV, Golaszewski S, Ladurner G. 2011. Preserved oscillatory response but lack of mismatch negativity in patients with disorders of consciousness. Clin Neurophysiol 122: 17441754.

Huberfeld G, Wittner L, Clemenceau S, Baulac M, Kaila K, Miles R, Rivera C. 2007. Perturbed chloride homeostasis and GABAergic signaling in human temporal lobe epilepsy. J Neurosci 27: 9866-9873.

Huberfeld G, Menendez de la Prida L, Pallud J, Cohen I, Le Van Quyen M, Adam C, Clemenceau S, Baulac M, Miles R. 2011. Glutamatergic pre-ictal discharges emerge at the transition to seizure in human epilepsy. Nat Neurosci 14: $627-634$.

Ibarz JM, Foffani G, Cid E, Inostroza M, Menendez de la Prida L. 2010. Emergent dynamics of fast ripples in the epileptic hippocampus. J Neurosci 30: 16249-16261.

Ikeda A, Taki W, Kunieda T, Terada K, Mikuni N, Nagamine T, Yazawa S, Ohara S, Hori T, Kaji R, et al. 1999. Focal ictal direct current shifts in human epilepsy as studied by subdural and scalp recording. Brain 122: 827-838.

Isomura Y, Fujiwara-Tsukamoto Y, Takada M. 2008. A network mechanism underlying hippocampal seizure-like synchronous oscillations. Neurosci Res 61: 227-233.

Jefferys JG, Menendez de la Prida L, Wendling F, Bragin A, Avoli M, Timofeev I, Lopes da Silva FH. 2012a. Mechanisms of physiological and epileptic HFO generation. Prog Neurobiol 98: 250-264.

Jefferys JGR, Jiruska P, de Curtis M, Avoli M. 2012b. Limbic network synchronization and temporal lobe epilepsy. In Jasper's basic mechanisms of the epilepsies (ed. Noebels JL, Avoli M, Rogawski MA, Olsen RW, Delgado-Escueta AV). National Center for Biotechnology Information, Bethesda, MD.

Jenssen S, Gracely EJ, Sperling MR. 2006. How long do most seizures last? A systematic comparison of seizures recorded in the epilepsy monitoring unit. Epilepsia 47: 14991503.

Jiruska P, de Curtis M, Jefferys JG, Schevon CA, Schiff SJ, Schindler K. 2013. Synchronization and desynchronization in epilepsy: Controversies and hypotheses. J Physiol 591: 787-797.

Kadam SD, White AM, Staley KJ, Dudek FE. 2010. Continuous electroencephalographic monitoring with radio-telemetry in a rat model of perinatal hypoxia-ischemia reveals progressive post-stroke epilepsy. J Neurosci 30: 404-415.

Kahane P, Minotti L, Francione S, Ryvlin P. 2006. The Bancaud and Talairach view on the epileptogenic zone: A working hypothesis. Epileptic Discord 8 (Suppl): S16S26.

Katz A, Marks DA, McCarthy G, Spencer SS. 1991. Does interictal spiking change prior to seizures? Electroencephalogr Clin Neurophysiol 79: 153-156.

Kohling R, Vreugdenhil M, Bracci E, Jefferys JG. 2000. Ictal epileptiform activity is facilitated by hippocampal $\mathrm{GABA}_{\mathrm{A}}$ receptor-mediated oscillations. J Neurosci 20: $6820-6829$.
Koubeissi MZ, Kahriman E, Syed TU, Miller J, Durand DM. 2013. Low-frequency electrical stimulation of a fiber tract in temporal lobe epilepsy. Ann Neurol 74: 223-231.

Kramer MA, Truccolo W, Eden UT, Lepage KQ, Hochberg LR, Eskandar EN, Madsen JR, Lee JW, Maheshwari A, Halgren E, et al. 2012. Human seizures self-terminate across spatial scales via a critical transition. Proc Natl Acad Sci 109: 21116-21121.

Lange HH, Lieb JP, Engel JJ, Crandall PH. 1983. Temporospatial patterns of pre-ictal spike activity in human temporal lobe epilepsy. Electroencephalogr Clin Neurophysiol 56: $543-555$.

Lasztoczi B, Nyitrai G, Heja L, Kardos J. 2009. Synchronization of GABAergic inputs to CA3 pyramidal cells precedes seizure-like event onset in juvenile rat hippocampal slices. J Neurophysiol 102: 2538-2553.

Lebovitz LB. 1979. Autorhythmicity of spontaneous interictal spike discharge at hippocampal penicillin focus. Brain Res 172: 35-55.

Leung SL, Lai PY, Davies DP. 1990. A survey of work undertaken in 1 year by a medical officer working in a maternal and child health clinic in Hong Kong: Implications for training. Ann Trop Paediatr 10: 99-108.

Levesque M, Salami P, Gotman J, Avoli M. 2012. Two seizure-onset types reveal specific patterns of high-frequency oscillations in a model of temporal lobe epilepsy. J Neurosci 32: 13264-13272.

Levesque M, Salami P, Behr C, Avoli M. 2013. Temporal lobe epileptiform activity following systemic administration of 4-aminopyridine in rats. Epilepsia 54: 596-604.

Librizzi L, de Curtis M. 2003. Epileptiform ictal discharges are prevented by periodic interictal spiking in the olfactory cortex. Ann Neurol 53: 382-389.

Lieb JP, Walsh GO, Babb TL. 1976. A comparison of EEG seizure patterns recorded with surface and depth electrodes in patients with temporal lobe epilepsy. Epilepsia 17: $137-160$.

Lopantsev V, Avoli M. 1996. Reverberation of chloride-dependent synaptic potentials in the rat entorhinal cortex in vitro. Neurosci Lett 210: 5-8.

Lopantsev V, Avoli M. 1998. Participation of $\mathrm{GABA}_{\mathrm{A}}$-mediated inhibition in ictal-like discharges in the rat entorhinal cortex. J Neurophysiol 79: 352-360.

Maillard L, Vignal JP, Gavaret M, Guye M, Biraben A, McGonigal A, Chauvel P, Bartolomei F. 2004. Semiologic and electrophysiologic correlations in temporal lobe seizure subtypes. Epilepsia 45: 1590-1599.

Marchi N, Granata T, Janigro D. 2014. Inflammatory pathways of seizure disorders. Trends Neurosci 37: 55-65.

Michalakis M, Holsinger D, Ikeda-Douglas C, Cammisuli S, Ferbinteanu J, DeSouza C, DeSouza S, Fecteau J, Racine RJ, Milgram NW. 1998. Development of spontaneous seizures over extended electrical kindling. I: Electrographic, behavioral, and transfer kindling correlates. Brain Res 793: 197-211.

Moran NF, Lemieux L, Kitchen ND, Fish DR, Shorvon SD. 2001. Extrahippocampal temporal lobe atrophy in temporal lobe epilepsy and mesial temporal sclerosis. Brain 124: 167-175. 
M. de Curtis and M. Avoli

Mormann F, Kreuz T, Andrzejak RG, David P, Lehnertz K, Elger CE. 2003. Epileptic seizures are preceded by a decrease in synchronization. Epilepsy Res 53: 173-185.

Nakagawa M, Durand D. 1991. Suppression of spontaneous epileptiform activity with applied currents. Brain Res 567: 241-247.

Netoff TI, Schiff SJ. 2002. Decreased neuronal synchronization during experimental seizures. J Neurosci 22: 7297 7307.

Ogren JA, Bragin A, Wilson CL, Hoftman GD, Lin JJ, Dutton RA, Fields TA, Toga AW, Thompson PM, Engel J Jr, et al. 2009. Three-dimensional hippocampal atrophy maps distinguish two common temporal lobe seizure-onset patterns. Epilepsia 50: 1361-1370.

Pacia SV, Ebersole JS. 1997. Intracranial EEG substrates of scalp ictal patterns from temporal lobe foci. Epilepsia 38: 642-654.

Pelliccia V, Mai R, Francione S, Gozzo F, Sartori I, Nobili L, Lo Russo G, Pizzanelli C, Tassi L. 2013. Ictal EEG modifications in temporal lobe epilepsy. Epileptic Disord 15: 392-399.

Perucca P, Dubeau F, Gotman J. 2014. Intracranial electroencephalographic seizure-onset patterns: Effect of underlying pathology. Brain 137: 183-196.

Pitkänen A, Kharatishvili I, Nissinen J, McIntosh TK. 2006. Posttraumatic epilepsy induced by lateral fluid-percussion brain injury in rats. In Models of seizures and epilepsy (ed. Pitkanen A, et al.), pp. 465-494. Elsevier, Berlin.

Pumain R, Menini C, Heinemann U, Louvel J, Silva-Barrat C. 1985. Chemical synaptic transmission is not necessary for epileptic seizures to persist in the baboon Papio papio. Exp Neurol 89: 250-258.

Ralston BL. 1958. The surgical treatment of epilepsy. NY State J Med 58: 3127-3133.

Rosenow F, Lüders H. 2001. Presurgical evaluation of epilepsy. Brain 124: 1683-1700.

Schevon CA, Weiss SA, McKhann G Jr, Goodman RR, Yuste R, Emerson RG, Trevelyan AJ. 2012. Evidence of an inhibitory restraint of seizure activity in humans. Nat Commun 3: 1060

Schindler K, Elger CE, Lehnertz K. 2007a. Increasing synchronization may promote seizure termination: Evidence from status epilepticus. Clin Neurophysiol 118: 19551968.

Schindler K, Leung H, Elger CE, Lehnertz K. 2007b. Assessing seizure dynamics by analysing the correlation structure of multichannel intracranial EEG. Brain 130: 65-77.

Seifert G, Carmignoto G, Steinhauser C. 2010. Astrocyte dysfunction in epilepsy. Brain Res Rev 63: 212-221.

Sherwin I. 1984. Ictal-interictal unit firing pattern differences in penicillin-induced primary and secondary epileptogenic foci. Exp Neurol 84: 463-477.

Spencer DD, Pappas CT. 1992. Surgical decisions regarding medically intractable epilepsy. Clin Neurosurg 38: 548566.

Spencer SS, Spencer DD. 1994. Entorhinal-hippocampal interactions in medial temporal lobe epilepsy. Epilepsia 35: $721-727$

Spencer SS, Guimaraes P, Katz A, Kim J, Spencer D. 1992. Morphological patterns of seizures recorded intracranially. Epilepsia 33: 537-545.
Stead M, Bower M, Brinkmann BH, Lee K, Marsh WR, Meyer FB, Litt B, Van Gompel J, Worrell GA. 2010. Microseizures and the spatiotemporal scales of human partial epilepsy. Brain 133: 2789-2797.

Steinhauser C, Boison D. 2012. Epilepsy: Crucial role for astrocytes. Glia 60: 1191.

Steinhauser C, Seifert G, Bedner P. 2012. Astrocyte dysfunction in temporal lobe epilepsy: $\mathrm{K}^{+}$channels and gap junction coupling. Glia 60: 1192-1202.

Talairach J, Bancaud J. 1966. Lesion, "irritative" zone and epileptogenic focus. Confin Neurol 27: 91-94.

Tassi L, Colombo N, Garbelli R, Francione S, Lo Russo G, Mai R, Cardinale F, Cossu M, Ferrario A, Galli C, et al 2002. Focal cortical dysplasia: Neuropathological subtypes, EEG, neuroimaging and surgical outcome. Brain 125: $1719-1732$

Tassi L, Colombo N, Cossu M, Mai R, Francione S, Lo Russo G, Galli C, Bramerio M, Battaglia G, Garbelli R, et al. 2005. Electroclinical, MRI and neuropathological study of 10 patients with nodular heterotopia, with surgical outcomes. Brain 128: 321-337.

Tassi L, Garbelli R, Colombo N, Bramerio M, Lo Russo G, Deleo F, Milesi G, Spreafico R. 2010. Type I focal cortical dysplasia: Surgical outcome is related to histopathology. Epileptic Disord 12: 181-191.

Tellez Zenteno JF. 2006. Can we consider thymectomy before pregnancy in female patients with myasthenia gravis? Eur J Cardiothorac Surg 30: 411-412; author reply 412.

Topolnik L, Steriade M, Timofeev I. 2003. Hyperexcitability of intact neurons underlies acute development of trauma-related electrographic seizures in cats in vivo. Eur $J$ Neurosci 18: 486-496.

Trevelyan AJ, Sussillo D, Watson BO, Yuste R. 2006. Modular propagation of epileptiform activity: Evidence for an inhibitory veto in neocortex. J Neurosci 26: 12447-12455.

Trevelyan AJ, Sussillo D, Yuste R. 2007. Feedforward inhibition contributes to the control of epileptiform propagation speed. J Neurosci 27: 3383-3387.

Trombin F, Gnatkovsky V, de Curtis M. 2011. Changes in action potential features during focal seizure discharges in the entorhinal cortex of the in vitro isolated guinea pig brain. J Neurophysiol 106: 1411-1423.

Trotter SA, Kapur J, Anzivino MJ, Lee KS. 2006. GABAergic synaptic inhibition is reduced before seizure onset in a genetic model of cortical malformation. J Neurosci 26: 10756-10767.

Truccolo W, Donoghue JA, Hochberg LR, Eskandar EN, Madsen JR, Anderson WS, Brown EN, Halgren E, Cash SS. 2011. Single-neuron dynamics in human focal epilepsy. Nat Neurosci 14: 635-641.

Uva L, Librizzi L, Wendling F, de Curtis M. 2005. Propagation dynamics of epileptiform activity acutely induced by bicuculline in the hippocampal-parahippocampal region of the isolated Guinea pig brain. Epilepsia 46: 1914-1925.

Uva L, Avoli M, de Curtis M. 2009. Synchronous GABAreceptor-dependent potentials in limbic areas of the in vitro isolated adult guinea pig brain. Eur J Neurosci 29: 911-920.

Velazquez JLP, Carlen PL. 1999. Synchronization of GABAergic interneuronal networks during seizure-like 
activity in the rat horizontal hippocampal slice. Eur J Neurosci 11: 4110-4118.

Velísek L. 1998. Extracellular acidosis and high levels of carbon dioxide suppress synaptic transmission and prevent the induction of long-term potentiation in the CA1 region of rat hippocampal slices. Hippocampus 8: 24-32.

Viitanen T, Ruusuvuori E, Kaila K, Voipio J. 2010. The $\mathrm{K}^{+}$-Cl cotransporter KCC2 promotes GABAergic excitation in the mature rat hippocampus. J Physiol 588: 15271540.

Wendling F, Bartolomei F, Bellanger JJ, Bourien J, Chauvel P. 2003. Epileptic fast intracerebral EEG activity: Evidence for spatial decorrelation at seizure onset. Brain 126: 1449-1459.

Wendling F, Hernandez A, Bellanger JJ, Chauvel P, Bartolomei F. 2005. Interictal to ictal transition in human temporal lobe epilepsy: Insights from a computational mode of intracerebral EEG. J Clin Neurophysiol 22: 343-356.

Wetherington J, Serrano G, Dingledine R. 2008. Astrocytes in the epileptic brain. Neuron 58: 168-178.
Williams PA, White AM, Clark S, Ferraro DJ, Swiercz W, Staley KJ, Dudek FE. 2009. Development of spontaneous recurrent seizures after kainate-induced status epilepticus. J Neurosci 29: 2103-2112.

Wu S, Kunhi Veedu HP, Lhatoo SD, Koubeissi MZ, Miller JP, Luders HO. 2014. Role of ictal baseline shifts and ictal high-frequency oscillations in stereo-electroencephalography analysis of mesial temporal lobe seizures. Epilepsia 55: 690-698.

Ylinen A, Bragin A, Nadasdy Z, Jando G, Szabo I, Sik A, Buzsaki G. 1995. Sharp wave-associated high-frequency oscillation $(200 \mathrm{~Hz})$ in the intact hippocampus: Network and intracellular mechanisms. J Neurosci 15: 3046.

Zhang ZJ, Koifman J, Shin DS, Ye H, Florez CM, Zhang L, Valiante TA, Carlen PL. 2012. Transition to seizure: Ictal discharge is preceded by exhausted presynaptic GABA release in the hippocampal CA3 region. J Neurosci 32: 2499-2512.

Ziburkus J, Cressman JR, Barreto E, Schiff SJ. 2006. Interneuron and pyramidal cell interplay during in vitro seizure-like events. J Neurophysiol 95: 3948-3954. 


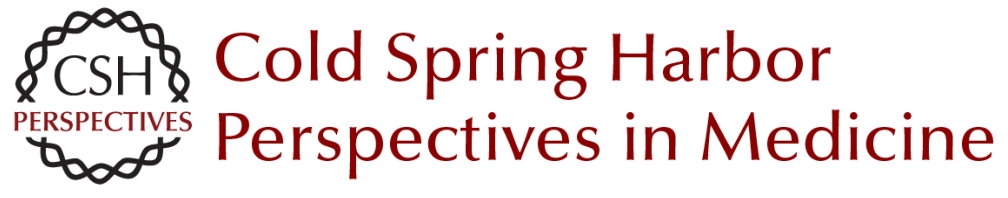

\section{Initiation, Propagation, and Termination of Partial (Focal) Seizures}

Marco de Curtis and Massimo Avoli

Cold Spring Harb Perspect Med 2015; doi: 10.1101/cshperspect.a022368

Subject Collection Epilepsy: The Biology of a Spectrum Disorder

The Epilepsy Spectrum: Targeting Future Research Challenges

Gregory L. Holmes and Jeffrey L. Noebels

Role of Sodium Channels in Epilepsy

David I. Kaplan, Lori L. Isom and Steven Petrou

\section{Mechanisms of Action of Antiseizure Drugs and the Ketogenic Diet Michael A. Rogawski, Wolfgang Löscher and Jong M. Rho}

Epilepsy and Autism

Ashura W. Buckley and Gregory L. Holmes

Immunity and Inflammation in Epilepsy Annamaria Vezzani, Bethan Lang and Eleonora Aronica

Hyperpolarization-Activated Cyclic Nucleotide-Gated (HCN) Channels in Epilepsy Gary P. Brennan, Tallie Z. Baram and Nicholas $P$. Poolos

The Role of Calcium Channels in Epilepsy Sanjeev Rajakulendran and Michael G. Hanna Interneuron Transplantation as a Treatment for Epilepsy

Robert F. Hunt and Scott C. Baraban

\section{Common Mechanisms Underlying \\ Epileptogenesis and the Comorbidities of \\ Epilepsy \\ Andrey Mazarati and Raman Sankar}

The Diathesis-Epilepsy Model: How Past Events Impact the Development of Epilepsy and Comorbidities Christophe Bernard

Potassium Channels in Epilepsy Rüdiger Köhling and Jakob Wolfart

\section{GABAergic Synchronization in Epilepsy Roustem Khazipov \\ Status Epilepticus \\ Syndi Seinfeld, Howard P. Goodkin and Shlomo Shinnar}

Neonatal and Infantile Epilepsy: Acquired and Genetic Models Aristea S. Galanopoulou and Solomon L. Moshé

\section{Epigenetics and Epilepsy \\ David C. Henshall and Katja Kobow}

Microcircuits in Epilepsy: Heterogeneity and Hub

Cells in Network Synchronization Anh Bui, Hannah K. Kim, Mattia Maroso, et al.

For additional articles in this collection, see http://perspectivesinmedicine.cshlp.org/cgi/collection/ 